\title{
Hearing Assessment of Neonates Treated in the Neonatal Intensive Care Unit of Besat Hospital in 2018-2019
}

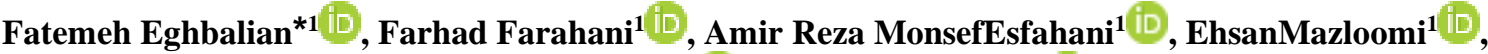 \\ Manoochehr Karami ${ }^{1 \text { (D), Mohammad Jafari }}{ }^{1}$ (D)
}

\section{Hearing Disorders Research Center, Besat Hospital, Hamadan University of Medical Sciences, Hamadan, Iran}

\begin{tabular}{|c|c|}
\hline Article Info & ABSTRACT \\
\hline doi $10.30699 / j a m b s .28 .127 .76$ & \multirow{2}{*}{$\begin{array}{l}\text { Background \& Objective: Early detection of neonatal hearing disorders is a } \\
\text { suitable measure of speech and behavioral development. The aim of this study was } \\
\text { to determine the prevalence of hearing disorder in high-risk neonates treated in a } \\
\text { neonatal intensive care unit (NICU). }\end{array}$} \\
\hline $\begin{array}{l}\text { Received: 2019/12/20; } \\
\text { Accepted: 2020/02/10; }\end{array}$ & \\
\hline Published Online: 01 Mar 2020; & \multirow{2}{*}{$\begin{array}{l}\text { Materials \& Methods: This descriptive study was performed on } 150 \text { neonates } \\
\text { treated in the NICU of Besat Hospital in Hamadan, Iran, using a census method. } \\
\text { Auditory brainstem response (ABR) and otoacoustic emission (OAE) tests were } \\
\text { performed by Labat and HOMOTH devices in Besat Hospital of Hamadan for } \\
\text { diagnosis of hearing disorders. Data were analyzed using descriptive statistics and } \\
\text { Chi-square test via SPSS } 16 \text {. }\end{array}$} \\
\hline \multirow[t]{2}{*}{$\begin{array}{l}\text { Use your device to scan and read the } \\
\text { article online }\end{array}$} & \\
\hline & $\begin{array}{l}\text { Results: In this paper, } 63.3 \% \text { of studied participants were male and } 36.7 \% \text { were } \\
\text { female. Also, } 4.7 \% \text { of participants had mild to severe hearing disorder, and } 3.3 \% \text { hac } \\
\text { moderately-severe hearing loss. There was a statistically significant relationship } \\
\text { between age at admission, hearing loss in both ears, and oxygen demand with hearing } \\
\text { impaired participants (ABR test). }\end{array}$ \\
\hline $\begin{array}{l}\text { Corresponding Information: } \\
\text { Fatemeh Eghbalian } \\
\text { Hearing Disorders Research Center, Besat } \\
\text { Hospital, Hamadan University of Medical }\end{array}$ & $\begin{array}{l}\text { Conclusion: Considering the presence of } 4.7 \% \text { of hearing-impaired neonates (ABR } \\
\text { test) in this study, it is necessary to design and implement a comprehensive hearing } \\
\text { screening for high-risk neonates in terms of hearing disorders. }\end{array}$ \\
\hline $\begin{array}{l}\text { Sciences, Hamadan, } \quad \text { Iran } \\
\text { E-Mail: eghbalian en@yahoo.com }\end{array}$ & $\begin{array}{l}\text { Keywords: Auditory brainstem response, Neonate, Otoacoustic emission } \\
\text { Screening }\end{array}$ \\
\hline (c) (1) (9) & $\begin{array}{l}\text { ss article distributed under the terms of the Creative Commons Attribution-noncommercial } 4.0 \text { International License which permits } \\
\text { ncommercial usages with proper citation. }\end{array}$ \\
\hline
\end{tabular}

\section{Introduction}

With the advancement of perinatal and neonatal medicine, as well as the development and equipping of neonatal intensive care units (NICUs), the survival of critically ill infants has increased today. One of the problems that infants have with birth is hearing disorder. In this regard, $80 \%$ of hearing reduction occurs in congenital infants, and this disorder does not occur until they reach the age of speech and language. Also, twothirds of infants have hearing parents, which causes parental attention to hearing problems in infants.

On the other hand, the prevalence of congenital hearing loss is 1 to 2 cases per 1000 live births, which is more common than disorders such as Congenital Hypothyroidism and Phenylketonuria (1-4). This disorder in infants with risk factors (birth weight less than $1250 \mathrm{~g}$, Apgar score less than 3 and 6 at 1, and 5min seizures, ventilator therapy, meningitis, jaundice) associated with Asphyxia, and Aminoglycoside; So, Furosemide treatment are more common (3-8). Hearing problems and brainstem dysfunction are also more common in neonates treated in ICUs $(9,10)$. Early detection of hearing disorders is a measure, which is suitable for speech and behavioral development $(11,12)$.

The importance of early auditory screening has long been recognized, with two main goals. The short-term goal is to diagnose hearing loss early. Its long-term goal is to perform timely interventions in the field of hearing rehabilitation, improving the prognosis of speech and cognitive development $(2,3,6,12)$. Organizations around the world have adopted nationwide hearing screening. Prior to 1990, hearing screening was performed on infants at risk. In 2000, the American Infant Surveillance Committee recommended a hearing examination of all infants before release from the hospital. In 2014, $97 \%$ of American infants were given a hearing test at birth. More than half of the infants with hearing loss were diagnosed. These issues indicated the need for a hearing test at birth (13).

Otoacoustic emission (OAE) testing has long been a standard practice for the neonatal hearing screening. On the other hand, the auditory brainstem response (ABR) test is a gold standard for assessing the auditory level 
(the function of the eighth nerve and the auditory pathways of the brainstem $(\mathbf{1 4 , 1 5 )}$. In this regard, studies have stated their goals in the diagnosis of infants with hearing loss before three months of age and the initiation of treatment and rehabilitation before six months of age (12). Moreover, hearing is a key solution for communication and the basis of learning. Therefore, this study was designed and implemented to evaluate hearing (ABR and OAE) of the neonates hospitalized and treated in NICU of Besat Hospital in Hamadan, Iran.

\section{Materials and Methods}

This cross-sectional descriptive study was performed on 150 neonates hospitalized and treated in NICU of Besat Hospital in 2018-2019 using an available census sampling method. Inclusion criteria included all neonates hospitalized and treated in NICU. Exclusion criteria included all neonates whose parents did not consent to participate in this study. Researchers were justified in obtaining informed written consent from the parents. The patients were enrolled in the study with the written informed consent of their parents. This study was approved by Hamadan University of Medical Sciences with a code of ethics (IR.UMSHA.REC.1396.158).

A researcher-made checklist was used to collect data. The checklist included the following variables: gender, gestational age (term, pre-term), birth weight (below $2700 \mathrm{~g}, 2700$ to $4200 \mathrm{~g}$, over $4200 \mathrm{~g}$ ), infant age at admission (under one week, one to two weeks, two to three weeks, more than three weeks), aminoglycoside intake (had, did not have), positive family history of hearing loss (has, does not have), needs oxygen (does, does not), the number of days in hospital (under one week, one to two weeks, two to three weeks, over three weeks), OAE test (Fail, Pass), ABR test (normal 0$25 \mathrm{db}$, mild $25-40 \mathrm{db}$, moderate $40-55 \mathrm{db}$, Moderate to severe 55-70db, severe 70-90db, deep more than 90db), reduction, hearing loss of both ears (right ear, left ear, both ears, none), use of furosemide (does, does not), respiratory (had, did not have), and neuropathy audiometry. The ABR test was performed using the Labat device made in Italy and the OAE test was performed using the Homoth device made in Germany. Hearing tests were performed by a hearing expert. (Leibnizstraße, Kaltenkirchen, Germany). SPSS 16 (SPSS Inc., Chicago, Ill., USA) was used to analyze the data. Descriptive statistics and Chi-square test were used to describe and analyze the data.

\section{Results}

Table1 shows the result of the demographic variables. According to the results, $63.3 \%$ of study participants were male, and $36.7 \%$ were female. The time of hospitalization was below one week of age.

Table 2 illustrates the hearing loss status of the participants. In this study, $3.3 \%$ of study participants had moderately-severe hearing loss.

Table 3 shows the results of the study participants' associations with hearing disorder (ABR test). A significant statistical relationship was found between age variables at infant hospitalization, oxygen demand, bilateral hearing loss, and OAE fail, with hearing disorder (ABR test).

Furthermore, between aminoglycoside intake, age, positive familial hearing loss, number of days of hospitalization, type of illness with hearing disorders (ABR test) were not significantly related. It showed that none of the participants in the study consumed furosemide. Also, none of the participants in the audiometric study had neuropathy.

Table 1. Results of Demographic Variables

\begin{tabular}{|c|c|c|c|c|}
\hline Demographic Variables & & Normal Hearing & Hearing Loss & $P$ \\
\hline \multirow{2}{*}{ Sex } & Female & $53(35.3)$ & $2(1.3)$ & \multirow{2}{*}{0.65} \\
\hline & Male & $90(60)$ & $5(3.3)$ & \\
\hline \multirow{2}{*}{ Gestational age } & Term & $103(68.7)$ & $6(4)$ & \multirow{2}{*}{0.42} \\
\hline & Pre-term & $40(26.7)$ & $1(0.7)$ & \\
\hline \multirow{3}{*}{ Birth Weight } & $\mathrm{BW}<2700 \mathrm{~g}$ & $37(24.7)$ & $0(0)$ & \multirow{3}{*}{0.27} \\
\hline & $2700<\mathrm{BW}<4200$ & $104(69.3)$ & $7(4.7)$ & \\
\hline & $\mathrm{BM}>4200$ & $2(1.3)$ & $0(0)$ & \\
\hline \multicolumn{2}{|l|}{ Total } & & $150(100)$ & \\
\hline
\end{tabular}

Table 2. Hearing Loss Status of Participants 


\begin{tabular}{|cc}
\hline Normal & $143(95 / 3)$ \\
Slight & $1(0 / 7)$ \\
Mild & $0(0)$ \\
Moderate & $1(0 / 7)$ \\
Moderately-Severe & $5(3 / 3)$ \\
Severe & $0(0)$ \\
\hline Profound & $0(0)$ \\
Total & $150(100)$ \\
\hline
\end{tabular}

Table 3. Results of the Relationship between Research Variables and Hearing Disorders of Study Participants

\begin{tabular}{|c|c|c|c|c|c|}
\hline \multicolumn{2}{|c|}{ Study variables } & $\begin{array}{c}\text { Normal ABR } \\
(0-25 \mathrm{db})\end{array}$ & $\begin{array}{c}\text { Abnormal } \\
\text { ABR(ABR }>25 \mathrm{db})\end{array}$ & Chi-Square & $\mathrm{P}$ \\
\hline \multirow{4}{*}{$\begin{array}{l}\text { Age at Infant } \\
\text { Hospitalization }\end{array}$} & Under a week & $94(62.7)$ & $3(2)$ & \multirow{4}{*}{10.31} & \multirow{4}{*}{0.01} \\
\hline & 1-2 weeks & $11(7.3)$ & $3(2)$ & & \\
\hline & 2-3 weeks & $19(12.7)$ & $1(0.7)$ & & \\
\hline & More than three weeks & $19(12.7)$ & $0(0)$ & & \\
\hline \multirow{2}{*}{ Aminoglycoside Intake } & yes & $7(4.7)$ & $0(0)$ & \multirow{2}{*}{0.36} & \multirow{2}{*}{0.55} \\
\hline & no & $136(90.7)$ & $7(4.7)$ & & \\
\hline \multirow{2}{*}{$\begin{array}{l}\text { Family History of } \\
\text { Hearing Disorders }\end{array}$} & yes & $3(2)$ & $1(0.7)$ & \multirow{2}{*}{3.82} & \multirow{2}{*}{0.05} \\
\hline & no & $140(95.3)$ & $6(4)$ & & \\
\hline \multirow{2}{*}{ Oxygen Needs } & yes & $7(4.7)$ & $2(1.3)$ & \multirow{2}{*}{6.63} & \multirow{2}{*}{0.01} \\
\hline & no & $136(90.7)$ & $5(3.3)$ & & \\
\hline \multirow{4}{*}{ Days of Hospitalization } & Under a week & $84(56)$ & $3(2)$ & \multirow{4}{*}{2.03} & \multirow{4}{*}{0.56} \\
\hline & $1-2$ weeks & $47(31.3)$ & $4(2.7)$ & & \\
\hline & 2-3 weeks & $7(4.7)$ & $0(0)$ & & \\
\hline & More than three weeks & $5(3.3)$ & $0(0)$ & & \\
\hline \multirow{2}{*}{ OAE } & Pass & $143(95.3)$ & $0(0)$ & \multirow{2}{*}{1.28} & \multirow{2}{*}{0.001} \\
\hline & Fail & $0(0)$ & $7(4.7)$ & & \\
\hline \multirow{4}{*}{ Hearing loss } & Right ear & $0(0)$ & $0(0)$ & \multirow{4}{*}{1.5} & \multirow{4}{*}{0.001} \\
\hline & Left ear & $0(0)$ & $1(0.7)$ & & \\
\hline & Both ears & $0(0)$ & $6(4)$ & & \\
\hline & None & $143(95.3)$ & $0(0)$ & & \\
\hline Total & Total & & $150(100)$ & & \\
\hline
\end{tabular}

\section{Discussion}

Based on the results of this study, $63.3 \%$ of study participants were male, and $36.7 \%$ were female. Also, $64.7 \%$ of study participants were less than a week old at the time of hospitalization. There was no statistically significant correlation between the gestational age and the birth weight with hearing disorder (ABR test), which was consistent with some similar studies $(\mathbf{1 6}, \mathbf{1 7})$. However, in some other studies, there was a correlation between the gestational age and the birth weight with hearing disorder. There was a statistically significant difference that could be attributed to the large sample size of the studies, which is consistent with the results of this study (18-20). Similar research, studying factors related to hearing disorders, have reported ototoxic drugs, mechanical ventilation, and low Apgar score at one and five min of birth $(21,22)$.

The results of this study showed that $3.3 \%$ of study participants had moderately-severe hearing loss. This finding is similar to a study conducted in high-risk newborns (23).

Based on the results of this study, the age of the patients at the time of hospitalization had significant statistical relationship with hearing disorders (ABR test), and the patients, who were less than two weeks old at the time of hospitalization, had more hearing disorder. This finding was less well-considered in similar studies. The results of this study showed the highest percentage of neonates hospitalized due to seizure. These findings are 
consistent with similar studies in neonatal hearing disorders, which have reported these seizures as one of the major causes of hearing disorder $(12,22)$. The results of this study showed that none of the participants in the study had Furosemide consumption. Also, none of the participants in the study needed a respirator and none of the participants had a neuropathic audiometry. This finding was inconsistent with some similar studies. The different nature of the patients was the cause of this difference (12). Based on the results of this study, there is a significant relationship between the need for oxygen and the hearing disorders (ABR test), and those who needed oxygen showed greater hearing disorders. This finding has been less well-considered in similar studies; the cause of this issue can be of a different therapeutic nature and different types of treatment for patients treated in different studies. However, these findings are consistent with the results reported by Umehara et al. The results of their study showed that the factors contributing to the elevation of ABR threshold were oxygen administration (22). There was a statistically significant relationship between the two variables of OAE and ABR in the study, and the participants, who were diagnosed with hearing disorder via the ABR test, also failed their OAE test.

This direct relationship between the two tests may indicate that persons hospitalized and treated in NICUs need both tests (ABR and OAE) at birth to make a definitive diagnosis of hearing disorders. This finding was also mentioned in the study carried out by Di Stadio et al. (24). In their study, $95.3 \%$ of the participants had a healthy hearing, and based on the results, $4 \%$ of study participants had hearing disorders. They also showed disorder in both ears, and $4.7 \%$ of participants in the study had mild to severe hearing disorder. This finding is in line with some similar studies $(9,25)$. It is recommended that programs be designed and implemented to inform ad follow up parents on the subject of hearing loss.

\section{Conclusion}

The two variables of "need for oxygen" and "age at hospitalization" can be considered as two important variables in the early diagnosis of neonatal hearing disorders in neonates admitted to NICU and care for newborn infants.

Significant statistics of hearing disorders in neonates with risk factors (such as having a history of seizures), showed a need to plan and perform national screening of both $\mathrm{ABR}$ and $\mathrm{OAE}$ tests in neonatal care.
Although it is mandatory to measure the hearing of all infants after birth, the aim of this study was to examine the hearing of infants admitted to the NICU ward of Besat Hospital in Hamadan using $\mathrm{ABR}$ and $\mathrm{OAE}$ methods. Based on the results of this study, it is necessary to perform ABR and OAE tests in all NICU infants before release so that the cases that have been associated with auditory nerve damage can be diagnosed and treated early, in order not to have various hearing problems in the future. As the retinopathy of prematurity (ROP) eye exam is performed on premature infants at 28 days of age, this study also found that ABR and OAE tests are required for all infants admitted to NICU for a variety of reasons.

In future studies, it is suggested that a similar study be performed with the case-control method.

\section{Acknowledgments}

This article results from the research design and financial support of the Vice President of Research and Technology of Hamadan University of Medical Sciences, so thanks for their support. Also, we would like to thank all the parents of the newborns for their contribution to this study.

\section{Conflict of Interest}

Authors declared no conflict of interest.

\section{References}

1. Suzuki N, Suzumura H. Relation between predischarge auditory brainstem responses and clinical factors in high-risk infants. PediatrInt. 2004;46(3):255-63.

[DOI:10.1111/j.1442200x.2004.01897.x]

2. De Capua B, De Felice C, Costantini D, Bagnoli F, Passali D. Newborn hearing screening by transient evoked otoacoustic emissions: analysis of response as a function of risk factors. ActaotorhinolaryngolItalica. 2003;23(1):16-20.

3. EghbalianF,RasuliB,Monsef F, Frequency, causes, and findings of brain CT scans of neonatal seizure at Besat hospital, Hamadan, Iran ,Iranian journal of child neurology;9 (1), 56.

4. Nabavi S, BehzadMoghadam M, Arab Hosseini M, Vaezi M, Rajabi R. Evaluation of Auditory Brainstem Responses (ABR) in healthy term infants with elevated bilirubin levels requiring exchange transfusion. J Adv Med Biomed Res. 2011; 19 (75) :77-83.

5. Swigonski N, Shallop J, Bull MJ, Lemons JA. Hearing screening of high risk newborns. Ear Hear. 
1987;8(1):26-30. 198702000-00005]

[DOI:10.1097/00003446-

6. Kazemi A, Ellenius J, Tofighi S, Salehi A, Eghbalian F, Fors UG. CPOE in Iran-a viable prospect?: Physicians' opinions on using $\mathrm{CPOE}$ in an Iranian teaching hospital. IntJMed Inform. 2009;78(3):199-207.

[DOI:10.1016/j.ijmedinf.2008.07.004]

7. Rhee CK, Park HM, Jang YJ. Audiologic evaluation of neonates with severe hyperbilirubinemia using transiently evoked otoacoustic emissions and auditory brainstem responses. laryngoscope. 1999;109(12):2005-8. [DOI:10.1097/00005537-199912000-00021]

8. Mjøen S, Langslet A, Tangsrud SE, Sundby A. Auditory brainstem responses (ABR) in high-risk neonates. ActaPædiatrica. 1982;71(5):711-5. [DOI:10.1111/j.1651-2227.1982.tb09508.x]

9. Vatovec J, Perat MV, Šmid L, Gros A. Otoacoustic emissions and auditory assessment in infants at risk for early brain damage. Int $\mathrm{J}$ Pediatr Otorhinolaryngol. 2001;58(2):139-45. [DOI:10.1016/S0165-5876(01)00419-0]

10. Trinidad GR, Pando JP, Vega AC, Serrano MB, Blasco AH. Early detection of hearing loss in neonates by using transient evoked otoacoustic emissions.

11. Spanish Children's Yearbook. 1999;50(2):166-71.

12. Morlet T, Ferber-Viart C, Putet G, Sevin F, Duclaux R. Auditory screening in high-risk preterm and full-term neonates using transient evoked otoacoustic emissions and brainstem auditory evoked potentials. IntJ PediatrOtorhinolaryngol. 1998;45(1):31-40. 5876(98)00081-0]

[DOI:10.1016/S0165-

13. Zahedpash Y, Ahmadpoor M, Aghajani R. Hearing screening following treatment of neonates in NICU. Iran J Pediatr. 2007;17(Suppl 1):14-20.

14. Hinton CF, Mai CT, Nabukera SK, et al. Developing a public health-tracking system for follow-up of newborn screening metabolic conditions: a four-state pilot project structure and initial findings. Genet Med. 2014;16(6):484. [DOI:10.1038/gim.2013.177]

15. Valkama AM, Laitakari KT, Tolonen EU, Väyrynen MR, Vainionpää LK, Koivisto ME. Prediction of permanent hearing loss in high-risk preterm infants at term age. EuropJ Pediatr. 2000;159(6):459-64.

[DOI:10.1007/s004310051308]

16. Bowes M, Smith C, Tan AK, Varette-Cerre P. Screening of high-risk infants using distortion product otoacoustic emissions. J OtolaryngolHead \& Neck Surg. 1999;28(4):181.
17. Ghirri P, Liumbruno A, Lunardi S. Universal neonatal audiological screening: experience of the University hospital of Pisa. ItalyJPediatr. 2011;37(1):16. [DOI:10.1186/1824-7288-37-16]

18. Korres S, Nikolopoulos TP, KomkotouV,et al. Newborn hearing screening: effectiveness, importance of high-risk factors, and characteristics of infants in the neonatal intensive care unit and well-baby nursery. Otol\&Neurotol. 2005;26(6):1186-90. [DOI:10.1097/01.mao.0000184602.94677.41]

19. Daghistani KJ, Jamal TS, Zakzouk SM. Hearing impairment in low birth weight. Saudi med J. 2002;23(3):311-3.

20. Valkama AM, Laitakari KT, Tolonen EU, Väyrynen MR, Vainionpää LK, Koivisto ME. Prediction of permanent hearing loss in high-risk preterm infants at term age. EuropJ Pediatr. 2000;159(6):459-64. [DOI:10.1007/s004310051308]

21. Hille ET, Van Straaten HL, Verkerk PH, Dutch NICU neonatal hearing screening working group. Prevalence and independent risk factors for hearing loss in NICU infants. Actapaediatrica. 2007;96(8):1155-8. [DOI:10.1111/j.16512227.2007.00398.x]

22. Vohr BR, Widen JE, Cone-Wesson B,et al. Identification of neonatal hearing impairment: characteristics of infants in the neonatal intensive care unit and well-baby nursery. Ear Hear. 2000;21(5):373-82. [DOI:10.1097/00003446200010000-00005]

23. Umehara T, Hosokawa S, Kita JY, Hayashi Y, Mineta H. Risk factors and prognostic factors of hearing impairment in neonatal intensive care unittreated infants. Audiol Neurotol. 2019;24(2):84-9. [DOI:10.1159/000500316]

24. Mandal S, Banerjee M, Ghosh P, Mallick AK, Kanjilal S. Early detection of hearing imparmant in high risk new-borns.PediatrOncall J. 2019; 16(4): 111-114. [DOI:10.7199/ped.oncall.2019.18]

25. Di Stadio A, Molini E, GambacortaV,et al. Sensorineuralhearing loss in newborns hospitalized in neonatal intensive care unit: An observational study. IntTinnitus J. 2019;23(1):31-6. [DOI:10.5935/0946-5448.20190006]

26. Taghdiri MM, Eghbalian F, EmamiF,et al. Auditory ealuation of high risk newborns by automated auditory brain stem response. Iran $\mathbf{J}$ Pediatr. 2008;18(4):330-4. 


\section{How to Cite This Article:}

Eghbalian F, Farahani F, Monsef Esfahani A R, Mazloumi E, Karami M, Jafari M. Hearing Assessment of Neonates Treated in the Neonatal Intensive Care Unit of Besat Hospital in 2018-2019. J Adv Med Biomed Res. 2020; 28 (127) :76-81

\section{Download citation:}

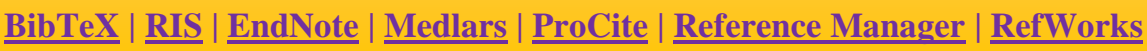

\section{Send citation to:}

Mendeley 2 Zotero (i)RefWorks $\underline{\text { RefWorks }}$ 